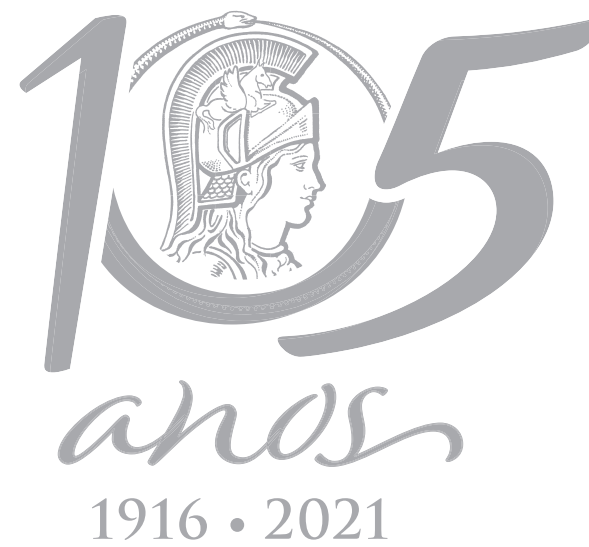

$1916 \cdot 2021$

\title{
ECOSYSTEMS
}

\section{Viability of sex identification of the blue- fronted Amazon parrot (Amazona aestiva) based on iris color sexual dichromatism}

\author{
ANTONIO I.S. NETO, EDMA S. DE ANTONIO, LAIZE TOMAZI, MÁRCIO B. DA SILVA \& \\ RICARDO E. FRAGA
}

\begin{abstract}
Reintroducing apprehended wild animal in a natural environment is a complex process that involves many steps, including rehabilitating individuals and ensuring viable populations for reproduction; as such, the proportion between males and females to be reintroduced need to be considered carefully. The need of specialized techniques to identify sex on species that do not present discernible sexual dimorphisms can be a hardship to a successful reintroduction. Amazona aestiva, one of the most apprehended species on Brazil, is an example of such case, as sexing techniques employed for it often involves molecular or surgical procedures. Some authors, however, describe potential sexual dimorphisms that could be discernible to the human eye, one of those being an iris color dichromatism between males and females that could present a more conventional way to discern sex on this species. We analyzed the viability of sex identification by direct observation of iris sexual dichromatism, comparing suggestions by professionals familiarized with the species to molecular sexing by Polymerase Chain Reaction (PCR) and measuring color similarity between individuals using digital colorimetry. We found no significant correspondence between sex indication based on direct observation and molecular sexing results, and no relationship between iris color and sex by colorimetric analysis.
\end{abstract}

Key words: Sexual dichromatism, molecular biology, blue-fronted amazon, colorimetry, wild animals.

\section{INTRODUCTION}

The Amazona genus is generally known for its parrots with vivid colors and ability to mimic sounds (Toft \& Wright 2016). Species from this genus can also present complex social behavior associated with sexual selection, although generally considered to be monomorphic (Schodde et al. 2013). Therefore, techniques to determine the sex of those species often involve surgical procedures such as laparoscopy (Taylor 1994) or specialized techniques such as magnetic resonance tomography (Grando, unpublished data). One of the most accurate, safe and recommended methods for determining sex on Amazona and other avian species is molecular sexing by Polymerase Chain Reaction (PCR). Amplifying genomic DNA with PCR allows the visualization of sexual alleles through electrophoresis, ensuring 99\% of accuracy (Griffiths et al. 1998). Molecular sexing is, however, a complex technique that requires specialized equipment and reagents to be applied.

Between the Amazona species, Amazona aestiva (Linnaeus, 1758) stands out as one of the most com mon within the illegal bird trade (ICMBio 2017). The high demand for commercialization of 
A. aestiva lead to it being considered one of the most apprehended avian species of Brazil (Costa et al. 2018). Institutions responsible for settling, rehabilitating and reintroducing apprehended individuals in a natural environment, such as Wildlife Screening Centers (CETAS), may face adversity reintroducing this high volume of individuals, considering that one key objective for a successful reintroduction is to guarantee a viable composition of males and females in a reintroduced population, and the high cost of sexing techniques available for A. aestiva (Armstrong \& Seddon 2008, BRASIL 2008, Barros et al. 2017).

However, sex identification of $A$. aestiva could be a less expensive and specialized procedure as some authors suggest evidence of sexual dimorphism presented in some characteristics of A. aestiva morphology's, such as body size (Berkunsky et al. 2009) and plumage color (Santos et al. 2006). Sick (1997) describes an apparently sexual dichromatism presented in iris coloration that could be discernible to the human eye; in his description, male individuals would present an orange-yellow iris and females an orange-red one. In avian species, the iris structure evolution is a topic associated to a plethora of hypothesis, with discussions about the functions of iris color patterns ranging from its role in age and sex identification during mate selection (Craig \& Hulley 2004, Nogueira \& Alves 2009) to its association with activity rhythm (Passarotto et al. 2018); some authors even suggest the possibility of iris color being correlated with light perception and vision accuracy (Savalli 1995).

We analyzed the viability of sex definition of $A$. aestiva by direct observation of this iris sexual dichromatism, comparing sex suggestions by conservation professionals with molecular sexing by PCR and measuring iris color similarity between male and female individuals using digital colorimetry. An analysis on this matter could benefit field studies as well as conservation practices involving this species, validating a convenient alternative for sex identification or preventing incorrect sex classification based on a subjective definition.

\section{MATERIALS AND METHODS}

\section{Data collection}

All activities conducted were approved by Federal University of Bahia's Multidisciplinary Health Institute (IMS/UFBA) Ethics Committee on the Use of Animals (CEUA- n 050/2017). Animals analyzed were hosted at Wildlife Screening Center of Vitória da Conquista (CETAS-VDC).

High quality photographs of the animal's eyes were taken using a digital camera (Nikon D3200 with AF-S DX NIKKOR 18-55 mm VR II lenses, using automatic settings for saturation, exposure, white balance and focus) provided by the wildlife screening center. Photographs were taken under indirect natural lightning, maintaining a medium distance of 1 meter between the photographer and the animal, and were saved in JPEG format. Prior photography, animals were captured and handled by professionals at the wildlife screening center. These parameters (especially the distance of photography and absence of external lightning) were taken to minimize startling the animals, as this could lead to a contraction or expansion of their pupils, a circumstance that could impact our analysis.

After photography, biological samples were collected from 44 ringed $A$. aestiva individuals by blood extraction from a cut in the animals' nails. After extraction, blood samples (stored in $110 \mathrm{~mm}$ filter paper strips) were transported to the Laboratory of Molecular Biology at Campus Anisio Teixeira, where they were stored in sterilized microcentrifuge tubes and left to dry 
for 1 hour in room temperature $\left(20^{\circ} \mathrm{C}\right)$ until DNA extraction.

\section{Sex identification by molecular sexing}

DNA extraction was done by washing the paper strips containing blood samples with a buffer solution (Tris $100 \mathrm{mM}-0,1 \%$ of SDS) and gentle agitation for 30 minutes. After removing the buffer solution, paper strips were washed again with ultrapure water and subjected to gentle agitation for another 30 minutes. After removing the water used for washing, another $50 \mathrm{uL}$ of ultrapure water was added to the tubes and the latter was submitted to a heated bath $\left(90^{\circ} \mathrm{C}\right)$ for 20 minutes. Lastly, the paper strips were discarded and the supernatant containing extracted DNA was stored at $-20{ }^{\circ} \mathrm{C}$ in a refrigerator until analysis.

Through polymerase chain reaction (PCR) using the enzyme Taq DNA Polymerase and a thermocycler, DNA fragments previously extracted from blood samples were amplified. Sex identification for each individual was provided by visualizing DNA bands after an electrophoretic run. Males were identified by the presence of a single band, representing the $\mathbf{Z}$ allele in homozygosis, while females were identified by the presence of two bands, referring to the $Z$ and $W$ alleles. Alleles were judged according to their size, whereas 396 bp characterized the $\mathrm{Z}$ allele and $412 \mathrm{bp}$ the $\mathrm{W}$ allele (Barros et al. 2017).

After molecular sexing, photographs were identified by sex and order of analysis, with male individuals distinguished by the initial letter " $M$ " and female individuals by the letter "F" (ex: M_01, F_01 and so on).

\section{Sex identification by direct observation}

The photographs of $A$. aestiva eyes were presented to three different professionals (two veterinarians and one biologist) with experience in wildlife conservation and in contact with $A$. aestiva for more than 8 years. Along images, a form was given to each observer for iris color classification in "orange-yellow" or "orange-red", according to the described sexual dichromatism.

\section{Image processing}

Prior to colorimetry analysis, photographs were edited using the open-source graphic editor GIMP 2.10.14. Firstly, we used the fuzzy selection tool to select and isolate the region of interest for our analysis, which was defined as between the outer limit and the inner limit of the iris, just before a brown region that demarcates the maximum range of pupil expansion (Figure 1a). Any obstructions (such as shadows) to the selected area were removed. After isolating the region of interest, a green masking ( $R G B$ value: $0,255,0$ ) was applied to the background of the picture for the sake of creating a precise parameter highlighting the limit of the region of interest to posterior analysis (Figure 1b).

\section{Colorimetric analysis}

Quantitative color profiling was done using the package "colordistance" for the R programming language. This package allows quantifying and categorizing all pixels composing an image individually according to their color; classifying them as coordinates in tridimensional color spaces that allows comparison based on similarity (Weller \& Westneat 2019). Before analysis, we set the package to ignore all values composing the green background masking.

Distinct observed iris color patterns were compared within the CIE Lab-space, a perceptually uniform color space that reflect the degree of difference between colors perceived by human vision as values classified in dimensions defined as "a (green-red)", "b (blueyellow)" and "Luminance" channels (Hill et al. 1997). Color pallets were created by measuring 


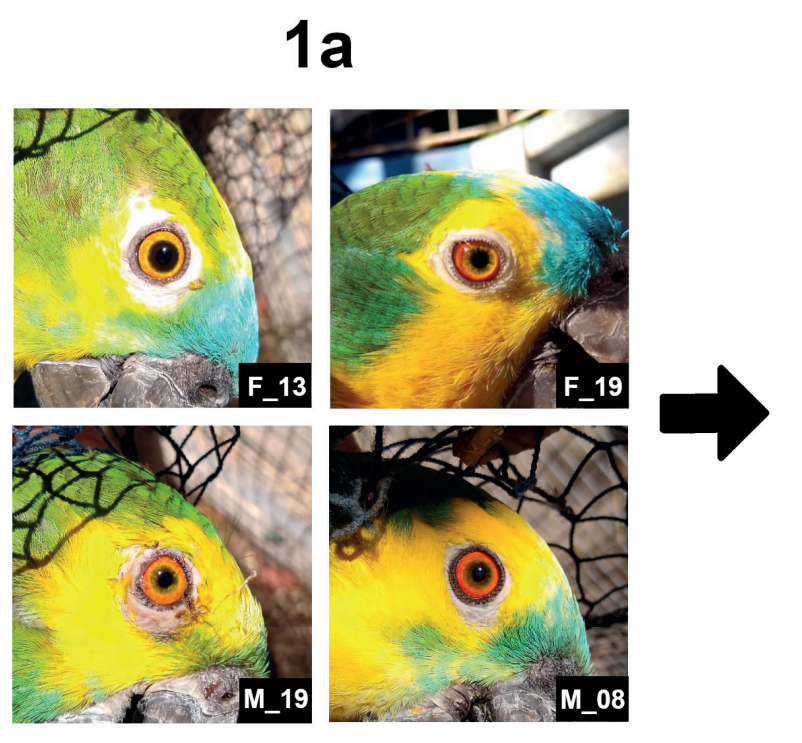

color composition of each image, emphasizing predominance of similar pixels color values.

Color similarity between males and females' irises were compared within the RGB color space, an additive color model that classifies each pixel in three dimensions according to their distribution of the three primary colors: red, green and blue (Loesdau et al. 2014).

\section{Statistical analysis}

To compare sex identification between observers and molecular sexing we used a multiple correspondence analysis (MCA), as well as chi-squared tests comparing accuracy of observers with each other and with PCR results. MCA compares categorical variables based on variance between observations, creating a low-dimensional map that allows visualization of correspondence among variables as points allocated according to similarity between each other (Johs 2018). Color similarity was defined according to RGB value distance between each individual pixel across images using a chi squared metric. Individuals were grouped in a symmetrical distance matrix based on iris color similarity.

\author{
Figure 1. Photographs \\ processing prior analysis. \\ This figures exhibit \\ images before (1a) and \\ after processing and \\ background masking (1b) \\ prior colorimetric analysis. \\ Identification started with \\ the letter " $M$ " refer to male \\ individuals, while the same \\ applied to the letter " $F$ " refer \\ to females.
}

\section{RESULTS}

We found though molecular sexing by PCR a proportion of 24 male individuals (54.55\%) and 20 females (45.45\%). Comparing observers' suggestions with molecular sexing (Table I), our multiple correspondence analysis showed disagreement between sex identification by direct observation of iris dichromatism and molecular sexing by PCR (Figure 2). Accuracy of sex identification based on iris dichromatism was significantly different from accuracy by PCR for each one of the observers $\left(X^{2}=1872.5\right.$, p-value < 2.2e-16 compared with a chi squared goodness-of-fit test) although sex suggestions between observers did not differ significantly from each other $\left(X^{2}=0.76688, p\right.$-value $=0.6815$ compared with a Pearson's chi squared test).

Associating unanimous color suggestions from observers with quantitative color profiling within the CIE Lab-space, we found no color pattern exclusive to males nor females, with individuals from both sexes presenting orangeyellow and orange-red irises patterns occupying similar ranges within CIE Lab dimensions (Figure 3). 
Table I. Observer's suggestions based on iris dichromatism compared to molecular sexing by PCR.

\begin{tabular}{|c|c|c|c|c|}
\hline Identification & $1^{\circ}$ Observer & $2^{\circ}$ Observer & $3^{\circ}$ Observer & PCR \\
\hline F_01 & Female & Female & Female & Female \\
\hline F_02 & Male & Female & Male & Female \\
\hline F_03 & Female & Female & Male & Female \\
\hline F_04 & Male & Male & Male & Female \\
\hline F_05 & Female & Female & Female & Female \\
\hline F_06 & Male & Male & Female & Female \\
\hline F_07 & Male & Male & Male & Female \\
\hline F_08 & Female & Male & Male & Female \\
\hline F_09 & Male & Male & Male & Female \\
\hline F_10 & Male & Male & Male & Female \\
\hline F_11 & Male & Female & Male & Female \\
\hline F_12 & Male & Female & Female & Female \\
\hline F_13 & Male & Male & Male & Female \\
\hline F_14 & Male & Male & Male & Female \\
\hline F_15 & Male & Male & Male & Female \\
\hline F_16 & Male & Male & Male & Female \\
\hline F_17 & Male & Male & Male & Female \\
\hline F_18 & Male & Female & Female & Female \\
\hline F_19 & Female & Female & Female & Female \\
\hline F_20 & Female & Female & Female & Female \\
\hline M_01 & Female & Female & Female & Male \\
\hline M_02 & Female & Male & Female & Male \\
\hline M_03 & Female & Female & Female & Male \\
\hline M_04 & Female & Male & Male & Male \\
\hline M_05 & Female & Female & Female & Male \\
\hline M_06 & Male & Male & Male & Male \\
\hline M_07 & Male & Female & Female & Male \\
\hline M_08 & Female & Female & Female & Male \\
\hline M_09 & Female & Female & Female & Male \\
\hline M_10 & Female & Female & Female & Male \\
\hline M_11 & Female & Female & Female & Male \\
\hline M_12 & Female & Female & Female & Male \\
\hline M_13 & Female & Female & Female & Male \\
\hline M_14 & Male & Male & Male & Male \\
\hline M_15 & Male & Male & Male & Male \\
\hline M_16 & Male & Male & Female & Male \\
\hline M_17 & Male & Male & Female & Male \\
\hline M_18 & Female & Female & Female & Male \\
\hline
\end{tabular}


Table I. Continuation.

\begin{tabular}{|c|c|c|c|c|}
\hline M_19 & Male & Male & Male & Male \\
\hline M_20 & Male & Male & Female & Male \\
\hline M_21 & Male & Female & Female & Male \\
\hline M_22 & Female & Female & Male & Male \\
\hline M_23 & Male & Male & Male & Male \\
\hline M_24 & Male & Female & Male & Male \\
\hline
\end{tabular}

Our classification analysis based on color similarity also presented no pattern associating exclusively males nor females. Irises were classified in two main hierarchical groups based on color similarity (Figure 4); one containing 13 individuals ( 5 males and 8 females) and the other containing 31 individuals (19 males and 12 females).

\section{DISCUSSION}

Due to a highly preserved CHD gene presented in sexual chromosomes of avian species, sex identification through molecular markers and electrophoresis visualization is considered one of the most reliable method for sex identification of Amazona aestiva and other species from the Amazona genus (Griffiths et al. 1998, Ciorpac et al. 2016, Barros et al. 2017). We identified the sex of 44 individuals through molecular sexing, with a proportion of 24 males and 20 females. Prevalence of males is a common recurrence among studies involving molecular sexing of avian species (Nebel et al. 2004, Cerit \& Avanus 2007, Barros et al. 2017).

Although sex identification by direct observation of sexual dichromatism can be considered an accurate methodology for some avian species (Farmer \& Holmgren 2000), our results imply no significant correspondence between sex suggestions based on iris sexual dichromatism and sexidentification by molecular sexing for $A$. aestiva. Color classification, while similar among observers, was not unanimously defined for all irises observed, indicating a degree of incoherence in distinction between the described iris dichromatism colors, "orangered" and "orange-yellow", even by professionals familiarized with $A$. aestiva.

Our color similarity matrix also did not present any pattern associating individuals' sex with iris color. Color profiling by software is a developing methodology for phenotypic color pattern characterization (Van Belleghem et al. 2017, Weller \& Westneat 2019, Hooper et al. 2020) and has been used before as a method to measure avian species dichromatism (Evans et al. 2010, Cake 2019, Gonzales \& Gonzalez 2020). Our converging results between colorimetric analysis and direct observation can attest the validity of this methodology.

Iris color patterns can have a range of functional roles among avian species. In passerine birds, although not common, sexual differences on iris coloration can serve as indicator for both sex and age, with some species presenting a degree of mate selection based on iris color as an indicator to the age of the partner (Craig \& Hulley 2004, Nogueira \& Alves 2009). There is evidence supporting coevolution of darker iris color patterns and nocturnality in owls' evolutionary histories, with hypothesis associating this correlation as an adaptative feature related to camouflage or concealment (Passarotto et al. 2018). Among Psittaformes, some species of the Cacatuidae family presents discernible iris color sexual dichromatism. This occurs in Eolophus roseicapilla (Vieillot, 1817), 


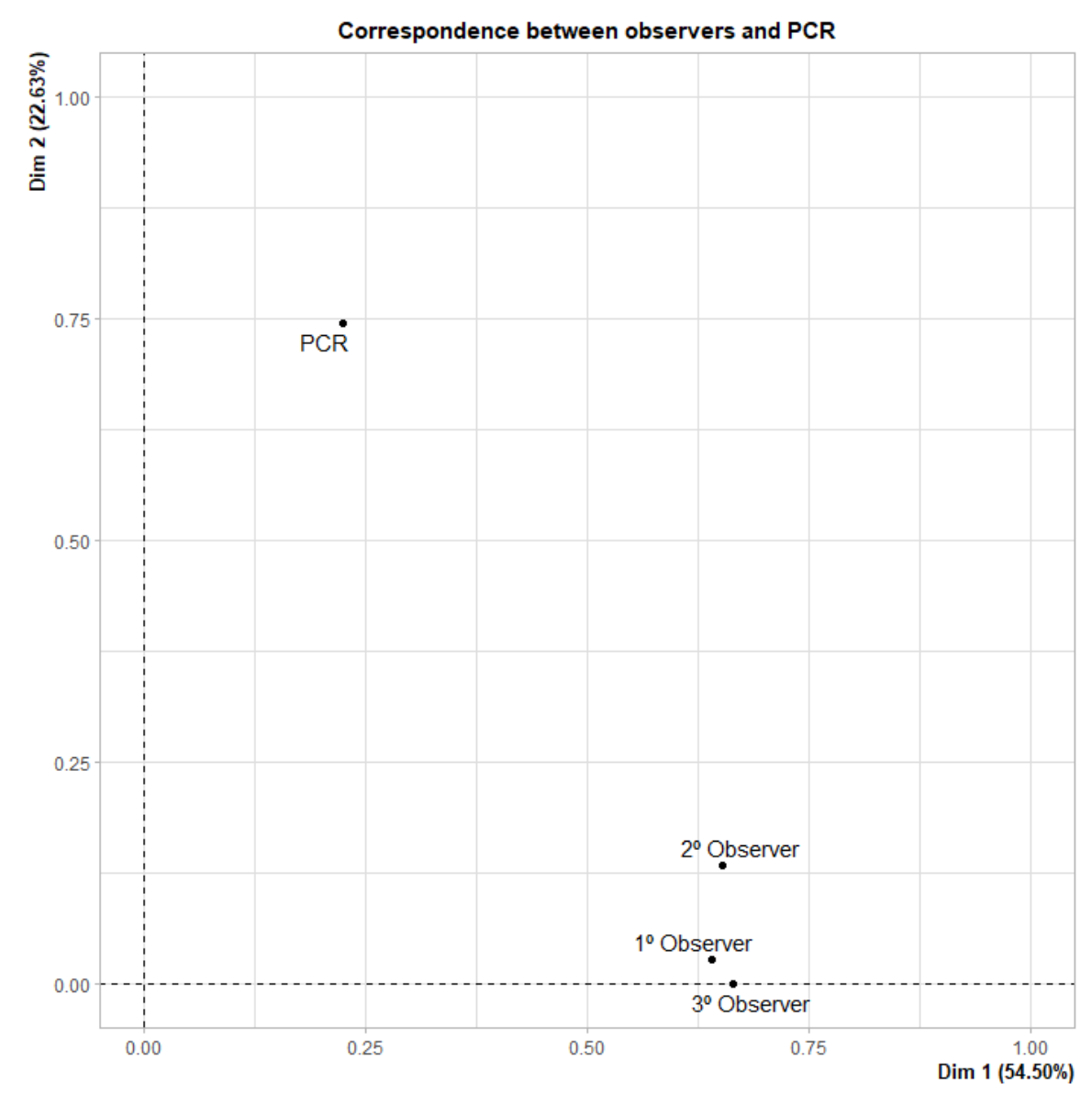

Figure 2. Proximity map relative to correspondence between observers and PCR. This figure illustrates the variables correspondence as a coordinate map, where points are allocated according to similarity or dissimilarity between observations. Variables with a similar profile are allocated closer to each other.
Lophocroa leadbeateri (Vigors, 1831) and Cacatua Alba (Müller, 1776), most notably (Forshaw 1989, Cameron 2007). Our results suggest that iris color sexual dichromatism is not present on Amazona aestiva, or if it does, it can't be determined by human observation nor digital colorimetry.

It is worth noting that our analysis was conducted with apprehended A. aestiva representants. The previously conditions of confinement could have an influence on iris pigmentation, as exposure to external substances has been documented before as a factor associated with changes in iris color patterns among particular bird species (Bortolotti et al. 2003) and captured A. aestiva individuals had demonstrated a sensibility to captivity relative to the concentration of androgens and other hormones in bloodstream (Deem et al. 2005). Such components are precursors to carotenoids, a class of pigments associated with yellow and red iris color patterns in some avian species (Oliphant 1987, Oliphant et al. 1992). A change of concentration of carotenoids related hormones was show to influence pigment deposition related to sexual dimorphism on particular passerine species (Lindsay et al. 2016).

Our results contrast with Santos et al. (2006), who suggests multiple-angle spectrometry as a viable alternative for sexing $A$. aestiva by analyzing plumage color of multiple body regions, such as forehead and wing tip, although this potential sexual dichromatism could not be recognized by the human eye. Berkunsky et al. (2009) suggests morphometrics as a viable alternative for sex identification of A. aestiva, as males would present larger size and weight compared to females. 

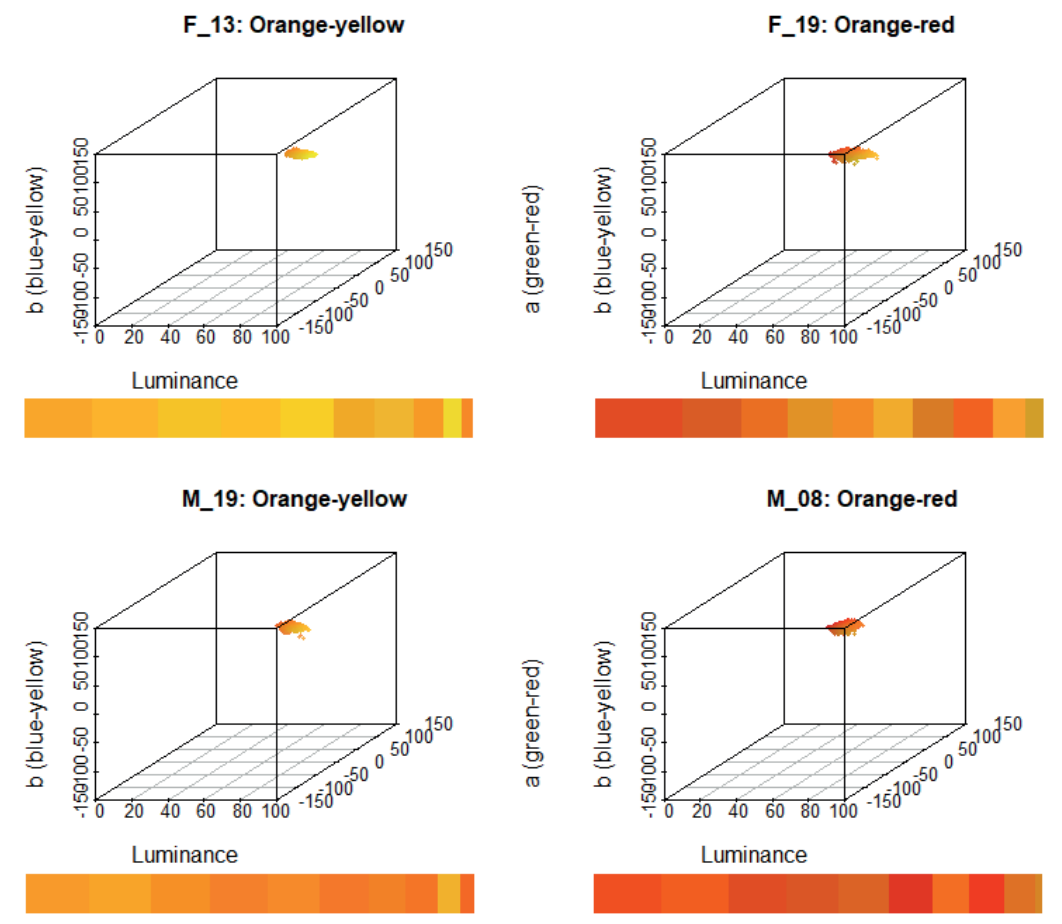

Figure 3. Analysis of color distribution within CIE Lab-space. Color definition for "orange yellow" or "orange red" was defined by agreement of all three observers. The three-dimensional space represents a quantitative classification of color based on Luminance ( $x$ axis), green-red ( $z$ axis) and blue-yellow (y axis) channels, and each point on the plot represents the color value of each individual pixel composing the image. Below each three-dimensional plot there is a color pallet exhibiting color predominance on each image based on pixel value similarity and distribution.

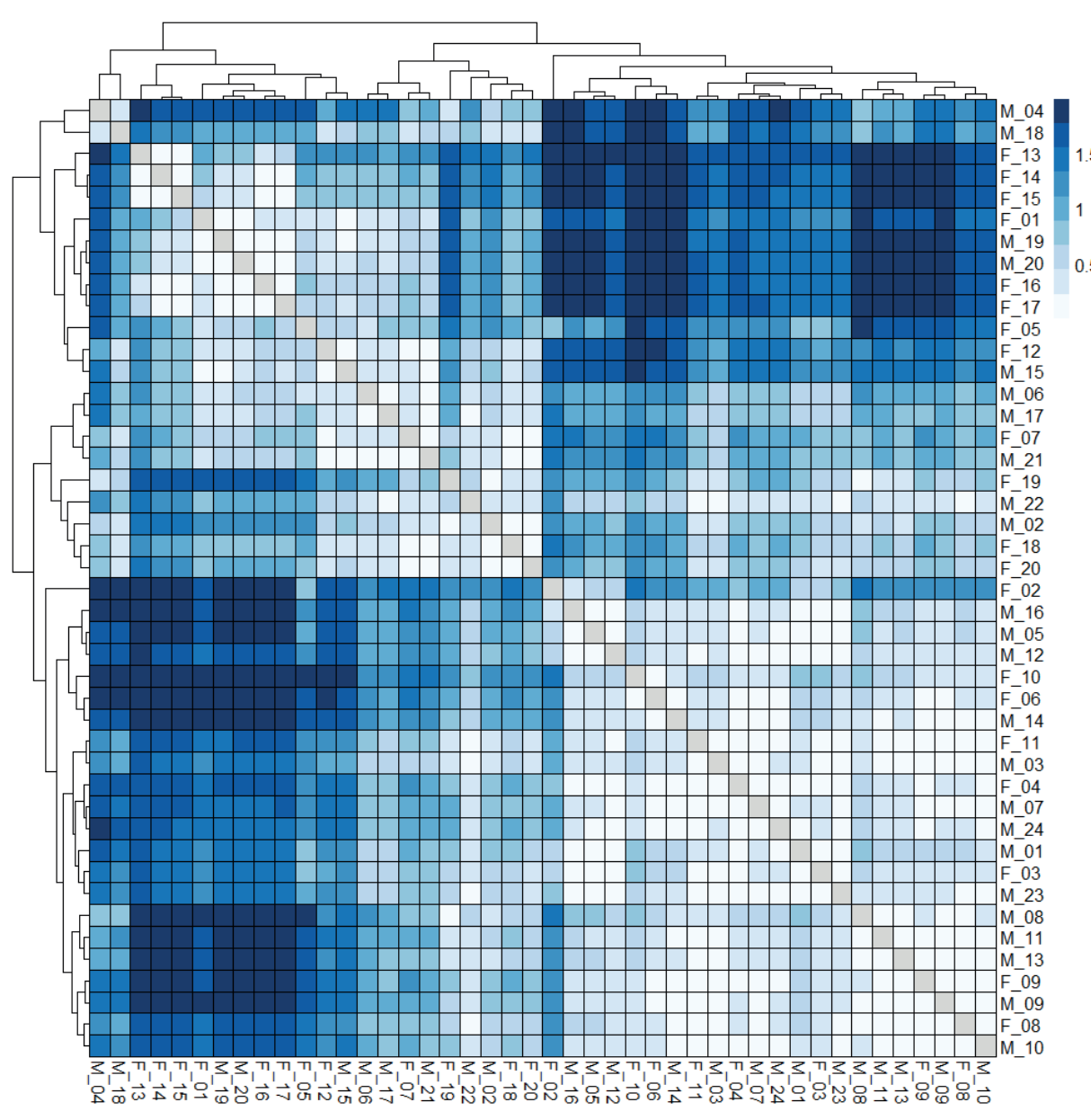

Figure 4. Color similarity clustered heatmap. This figure illustrates iris

1.5 color similarity between analyzed $A$. aestiva individuals. Identification started with the letter " $\mathrm{M}$ " refer to male individuals, while the same applied to the letter " $F$ " refer to females. In this plot, a lower value (lighter color) indicates higher similarity between compared individuals, while a higher value (darker color) designates otherwise. A double dendrogram specify similarity relationships between analyzed individuals, grouping them in clusters based on color proximity. 


\section{Acknowledgments}

We would like to thank the Centro de Triagem de Animais Silvestres de Vitória da Conquista (CETAS-VDC) for collaboration with data collection and the Conselho Nacional de Desenvolvimento Científico e Tecnológico (CNPq) for a research grant involving colorimetric analysis application and professor Alexandre Schiavetti for valuable input and suggestions on this manuscript.

\section{REFERENCES}

ARMSTRONG DP \& SEDDON PJ. 2008. Directions in reintroduction biology. Trends Ecol Evol 23(1): 20-25.

BARROS TB ET AL. 2017. Improvement of the Molecular Sexing of Parrots in the State of Bahia. Acta Biol Par 46(4): 89-107.

BERKUNSKY I, MAHLER B \& REBOREDA JC. 2009. Sexual dimorphism and determination of sex by morphometrics in Blue-fronted Amazons (Amazona aestiva). Emu 109(3): 192-197.

BORTOLOTTI GR, SMITS JE \& BIRD DM. 2003. Iris colour of American kestrels varies with age, sex, and exposure to PCBs. Physiol Biochem Zool 76(1): 99-104.

BRASIL. 2008. Instrução Normativa $n^{0} 179$, de 25 de junho de 2008. Ibama: 13.

CAKE M. 2019. Regional variation in iris colour of the White-browed Scrubwren Sericornis frontalis complex in digital photographs. Aust Field Ornithol 36(0).

CAMERON M. 2007. Reproduction. In: Cockatoos CSIRO Publishing Collingwood, Vic, 129-137 p.

CERIT H \& AVANUS K. 2007. Sex determination by CHDW and CHDZ genes of avian sex chromosomes in Nymphicus hollandicus. Turk J Vet Anim Sci 31(6): 371-374.

CIORPAC M ET AL. 2016. CHD genes: A reliable marker for bird populations and phylogenetic analysis? Case study of the superfamily Sylvioidea (Aves: Passeriformes). Turk J Zool 40(5): 749-757.

COSTA FJV ET AL. 2018. Espécies de Aves Traficadas no Brasil. Front. J Soc Technol Environ Sci (Anápolis) 7(2): 324-346.

CRAIG A \& HULLEY P. 2004. Iris colour in passerine birds: Why be bright-eyed?. S Afr J Sci 100(11): 584-588.

DEEM SL ET AL. 2005. Health evaluation of free-ranging and captive blue-fronted Amazon parrots (Amazona aestiva) in the Gran Chaco, Bolivia. J Zoo Wildl Med 36(4): 598-605.
EVANS SR ET AL. 2010. Age, sex and beauty: Methodological dependence of age- and sex-dichromatism in the great tit Parus major. Biol J Linn Soc 101(4): 777-796.

FARMER C \& HOLMGREN MA. 2000. SEXUAL DICHROMATISM IN THE PLUMAGE OF JUVENILE BROWN-HEADED COWBIRDS. J Field Ornithol 71(3): 429-436.

FORSHAW JM. 1989. Parrots in the Neotropical Distribution. In: Parrots of the World. $3^{\text {rd }}$ ed., Lansdowne Editions: Sydney, 77-144 p.

GONZALES JA \& GONZALEZ JC. 2020. Sexual dimorphism in eye coloration of Philippine Rufous Hornbills (Buceros hydrocorax and Buceros mindanensis). Hornbill Nat Hist \& Conserv 1(2).

GRIFFITHS R ET AL. 1998. A DNA test to sex most birds. Mol Ecol 7(8): 1071-1075.

HILL B, ROGER TH \& VORHAGEN FW. 1997. Comparative analysis of the quantization of color spaces on the basis of the CIELAB color-difference formula. ACM Trans Graph 16(2): 109-154.

HOOPER S, WELLER H \& AMELON S. 2020. Countcolors, an R Package for Quantification of the Fluorescence Emitted By Pseudogymnoascus Destructans Lesions on the Wing Membranes of Hibernating Bats. J Wildl Dis 56(4).

ICMBIO - INSTITUTO CHICO MENDES DE CONSERVAÇÃO DA BIODIVERSIDADE. 2017. Cartilha incentiva a preservação de papagaios. Available at: http://www.icmbio.gov. br/portal/ultimas-noticias/20-geral/8767-cartilhaincentiva-a-preservacao-de-papagaios (Accessed: 12 August 2020).

JOHS H. 2018. Multiple correspondence analysis. In: Multiple Correspondence Analysis For The Social Sciences, Routledge, 31-55 p.

LINDSAY WR ET AL. 2016. Testosterone activates sexual dimorphism including male-Typical carotenoid but not melanin plumage pigmentation in a female bird. J Exp Biol 219(19): 3091-3099.

LOESDAU M, CHABRIER S \& GABILLON A. 2014. Hue and Saturation in the RGB Color Space. Lect Notes Comput Sci: 203-212.

NEBEL S, CLOUTIER A \& THOMPSON GJ. 2004. Molecular sexing of prey remains permits a test of sex-biased predation in a wintering population of western sandpipers. Proc Royal Soc B 271(Suppl. 5): 321-323.

NOGUEIRA D \& ALVES M. 2009. Iris colour as an indicator of age feature in female Brazilian tanagers (Passeriformes: Emberizidae) confirmed by a molecular sexing technique. Rev Biol Trop 56: 1629-1633. 
OLIPHANT LW. 1987. Pteridines and purines as major pigments of the avian iris. Pigment Cell Res 1(2): 129-131.

OLIPHANT LW, HUDON J \& BAGNARA JT. 1992. Pigment Cell Refugia in Homeotherms-The Unique Evolutionary Position of the Iris. Pigment Cell Res 5(6): 367-371.

PASSAROTTO A ET AL. 2018. The evolution of iris colour in relation to nocturnality in owls. J Avian Biol 49(12).

SANTOS SICO, ELWARD B \& LUMEIJ JT. 2006. Sexual dichromatism in the blue-fronted Amazon parrot (Amazona aestiva) revealed by multiple-angle spectrometry. J Avian Med Surg 20(1).

SAVALLI UM. 1995. The Evolution of Bird Coloration and Plumage Elaboration. CUOR 12: 141-190.

SCHODDE R ET AL. 2013. Higher classification of new world parrots (psittaciformes; arinae), with diagnoses of tribes. Zootaxa 3691(5): 591-596.

SICK H. 1997. Ordem Psittaciformes. In: Ornitologia brasileira, Editora Nova Fronteira, 351 p.

TAYLOR WM. 1994. Endoscopic examination and biopsy techniques. In: Avian Medicine: Principles and Applications. 1994 Winger Publishing, 327-354 p.

TOFT CA \& WRIGHT TF. 2016. THE EVOLUTION OF PARROTS. In: Parrots of the wild: a natural history of the world's most captivating birds. $1^{\text {st }}$ ed., University of California Press, 235-237 p.

VAN BELLEGHEM SM ET AL. 2017. Patternize: An R package for quantifying color pattern variation. bioRxiv 38(1): 42-49.

WELLER HI \& WESTNEAT MW. 2019. Quantitative color profiling of digital images with earth mover's distance using the R package colordistance. Peer J 2019(2): 1-31.

\section{How to cite}

NETO AIS, DE ANTONIO ES, TOMAZI L, DA SILVA MB \& FRAGA RE. 2021. Viability of sex identification of the blue-fronted Amazon parrot (Amazona aestiva) based on iris color sexual dichromatism. An Acad Bras Cienc 93: e20210060. DOI 10.1590/0001-3765202120210060.
Manuscript received on January 14, 2021;

accepted for publication on July 15, 2021

\section{ANTONIO I.S. NETO}

https://orcid.org/0000-0003-0136-7210

EDMA S. DE ANTONIO 2

https://orcid.org/0000-0003-1280-8472

\section{LAIZE TOMAZI}

https://orcid.org/0000-0003-0977-8508

\section{MÁRCIO B. DA SILVA ${ }^{2}$}

https://orcid.org/0000-0002-6497-7924

\section{RICARDO E. FRAGA ${ }^{2}$}

https://orcid.org/0000-0001-9345-4869

${ }^{1}$ Programa de Pós-Graduação em Ecologia e

Conservação da Biodiversidade (PPGECB), Universidade Estadual de Santa Cruz (UESC), Pavilhão Prof. Max de Menezes, $1^{\circ}$ andar, sala 1DA, Rodovia Jorge Amado, Km 16, Salobrinho, 45662-900 Ilhéus, BA, Brazil

${ }^{2}$ Instituto Multidisciplinar em Saúde, Campus Anísio Teixeira, Universidade Federal da Bahia, Rua Rio de Contas, 58,

Candeias, 45029-094 Vitória da Conquista, BA, Brazil

\section{Correspondence to: Antonio I.S. Neto}

E-mail:neto.sodre@gmail.com

\section{Author Contributions}

Antonio I. Sodré Neto was responsible for the majority of data collection, data analysis and redaction. Ricardo Evangelista Fraga and Márcio Borba da Silva assisted with data collection including photographs and biological samples assembling. Laize Tomazi contributed with manuscript revision and assisted redaction. Edma Santos de Antônio provided assistance with molecular sexing routines and analysis.

(cc) BY 